\title{
PARAGUAY: DE LAS VIOLACIONES A LOS \\ DERECHOS HUMANOS A LA JUSTICIA TRANSICIONAL
}

PARAGUAY: VIOLATIONS OF HUMAN RIGHTS TO TRANSITIONAL JUSTICE

Recibido: 18 de 0ctubre del 2013 | Aceptado: 29 de Abril del 2014

\author{
MAITANE ARNOSO MARTÍNEZ $Z_{1}$;MANUEL CÁRDENAS CASTRO 2 ; DARÍO PÁEZ ROVIRA 3 ; CARLOS MARTÍN BERISTAIN 4 \\ (UNIVERSIDAD DEL PAÍ́s VASC0, País Vasco, España)
}

\section{RESUMEN}

Objetivo: Se analiza el impacto de las violaciones a los derechos humanos cometidas durante la dictadura de Stroessner (1954-1989) en Paraguay. Método: Se obtienen datos de 400 participantes residentes en las zonas más afectadas por la represión paraguaya. Se evaluó el impacto emocional, los efectos sobre la participación social y la percepción de la población sobre las medidas transicionales implementadas. Resultados: se desprende que este periodo, de gran impacto en las zonas rurales, evoca emociones negativas, acompañadas una alta necesidad de conversar socialmente sobre lo ocurrido en dicho período. También se constata una alta percepción de que las víctimas no lograrán perdonar a los responsables de la violencia. Conclusión: La población conoce y valora positivamente las medidas que se han adoptado en relación al pasado, aunque percibe negativamente el clima emocional del país. Este clima social se asocia a un menor deseo de alcanzar la reconciliación, que asciende entre quienes conocen y consideran sinceras y eficaces las disculpas pronunciadas por Lugo. La participación en audiencias públicas se asocia a mayor participación comunitaria, aunque también a mayor emocionalidad negativa.

PALABRAS CLAVE: Paraguay, dictadura, represión, derechos humanos, justicia transicional.

\section{ABSTRACT}

Objective: The impact of human rights violations committed in Paraguay during the Stroessner dictatorship (1954-1989) was analyzed. Method: Data were obtained from 400 participants living in the areas most affected by repression. The emotional impact was assessed, as were the impact on social participation and the perception of the public regarding the transitional measures, which were implemented. Results: It is shown that this period, which had great impact in rural areas, evokes negative emotions which are accompanied by a strong need for social conversation about what happened during that time. Also observed is a strong perception that victims will not succeed in forgiving those responsible for the violence. Conclusion: The population knows and attaches positive value to the measures taken in relation to the past, but negatively perceives the emotional climate of the country. This social climate is associated with a lessened desire to achieve reconciliation, which rises among those who are aware of the apologies given by Lugo and believe them to be sincere. Participation in public hearings is associated with greater community participation, but also with high negative emotionality.

KEY WORDS: Paraguay, dictatorship, repression, human rights, transitional justice. 


\section{INTRODUCCIÓN}

Desde la década de los 50, distintas dictaduras militares asolaron Latino América, casi todas ellas instauradas mediante cruentos golpes de Estado que se mantuvieron el poder gracias a la fuerte represión ejercida sobre la sociedad civil.

En Paraguay, la dictadura de Stroessner comenzó con el golpe de Estado el 4 de mayo de 1954 y durante los 35 años que se prolongó, se cometieron graves y extensas violaciones de derechos humanos. Se puede estimar que durante el régimen de Stroessner al menos 19.862 personas fueron detenidas en forma arbitraria o ilegal, 18.772 fueron torturadas, 58 ejecutadas extrajudicialmente, 337 desaparecidas y 3.470 exiladas (Comisión Verdad y Justicia, 2008). Prácticamente ninguna persona detenida se salvó de la tortura y casi todas las víctimas fueron objeto de esta grave violación de derechos humanos. Formar parte de un sector social, como por ejemplo las Ligas Agrarias 0 el movimiento estudiantil, de los partidos de oposición o de los incipientes movimientos armados (Frente Unido de Liberación Nacional o la Organización Político Militar), fue considerado un motivo suficiente para convertirse en víctima de la violencia estatal. La sospecha se extendió hacia todos los sectores sociales que no mostrasen una adhesión explícita al régimen. Las privaciones ilegales de la libertad y las torturas afectaron de modo más acusado a los miembros de partidos políticos y de los movimientos sociales que se encontraban más vulnerables dada su posición social y su localización geográfica, como es el caso de los campesinos y las personas de zonas rurales. El mayor número de desapariciones forzadas y de ejecuciones extrajudiciales se dirigió contra presuntos miembros de grupos armados.

Asimismo, se estima que cerca de 107.987 personas fueron víctimas indirectas de la violencia ejercida por el Estado, esto es, familiares o allegados cercanos de las víctimas que sufrieron directamente las violaciones de sus derechos humanos. En estas personas, las consecuencias psicológicas y sociales negativas que tuvieron los hechos de violencia fueron evidentes e impactaron sus vidas de un modo duradero (Comisión Verdad y Justicia, 2008). En este mismo sentido, los efectos de las violaciones de derechos humanos no solamente afectaron a un enorme número de víctimas individuales y familiares, sino que también afectaron a comunidades enteras.

En la década de los setenta, las comunidades campesinas fueron violentamente reprimidas, en particular las vinculadas a las Ligas Agrarias Cristianas, sobre todo en los departamentos de San Pedro, Caaguazú, Alto Paraná, Paraguari o Misiones, entre otras. Dichas comunidades constituian experiencias de resistencia no violenta a la dictadura, en un movimiento de origen cristiano que propugnaba por la autogestión económica, la concientización, la educación alternativa y la autoorganización política. También, durante este régimen se desconoció la dignidad humana de los indígenas y se cometieron graves violaciones a sus derechos humanos. Ejemplo de ello fueron los ataques de civiles y militares contra comunidades de los Pueblos Aché, Ayoreo, Maskoy y Toba Qom, donde se realizaron ejecuciones extrajudiciales de adultos, niños y ancianos, así como violaciones sexuales a las mujeres de dichos poblados. Finalmente, las violaciones de derechos humanos estuvieron acompañadas de pérdidas materiales y de tierras que fueron usurpadas y adjudicadas ilegalmente.

\section{Los procesos de justicia transicional}

En distintos países, en el tránsito de un período de violencia a un período de paz y democracia, se han puesto en marcha mecanismos de justicia transicional que han tratado de abordar los procesos de 
reconstrucción de la verdad, así como las posibilidades de hacer justicia y reparar material y simbólicamente a las víctimas de las violaciones masivas de derechos humanos. Entre las medidas más conocidas se encuentran las Comisiones de la Verdad (CV), que han sido creadas con el fin expreso de hacer frente al pasado de violaciones a los derechos humanos. Dichas comisiones pueden ser entendidas como rituales transicionales que buscan implementar un conjunto de mecanismos que avancen hacia la consolidación de normas y el refuerzo de la cohesión social en aras de evitar la aparición de la violencia en el futuro y recuperar la confianza institucional vulnerada en el período de violencia política (Beristain, Páez, Rimé y Kanyangara, 2010).

Además, las CV son un foro en que las víctimas pueden entregar su testimonio, hablar sobre aquello que les ocurrió en el pasado y transmitir su experiencia, validando su sufrimiento y promoviendo la empatía entre quienes les escuchan (Beristain, 2005). Desde la década del setenta hasta nuestros días, se han establecido más de treinta comisiones oficiales en el mundo (Avruch, 2010). Entre las funciones comunes a las diferentes CV se encuentran: a) el esfuerzo por construir una verdad sobre el periodo de violencia colectiva, b) reconocer y validar el sufrimiento de las víctimas, c) reparar material y simbólicamente a los afectados, d) contribuir a crear una memoria colectiva inclusiva orientada al futuro, e) prevenir nuevos actos de violencia y f) ayudar a la búsqueda de justicia. Estas funciones contribuirían a prevenir los ciclos de venganza y evitar nuevos crímenes de guerra, así como avanzar en sentido de reconciliar a los grupos enfrentados hasta entonces (Sikkink y Bott-Walling, 2007).

En los países de América Latina en los que se han desarrollado CV eficaces se ha constatado un incremento estadísticamente significativo del respeto por los derechos humanos, mientras que esto no ocurría en los países sin comisiones o con comisiones que no funcionaron (Beristain et al, 2010).

También basadas en el derecho a la verdad, en algunos países se han desarrollado procesos de exhumación. Las exhumaciones y la recuperación de los cuerpos de las personas asesinadas tras periodos de graves violaciones a los derechos humanos, constituyen la prueba fundamental del delito, sobre todo en contextos donde se llevaron a cabo desapariciones forzadas o ejecuciones en fosas comunes ocultando el destino de las víctimas. Aunque al igual que las comisiones pueden constituir medidas que, a partir del derecho a la verdad sirvan para impulsar procesos penales y de castigo hacia los responsables, las exhumaciones cumplen además otros objetivos: a nivel familiar, contribuyen en los procesos de duelo y dan a los seres queridos la posibilidad de enterrar a sus muertos de acuerdo a las normas socioculturales propias de una sociedad. A nivel comunitario, la recuperación de los restos son un indicador de la existencia de la represión y del reconocimiento del daño causado, permitiendo abrir el debate sobre temas claves en la historia social de un país (Pérez-Sales y Navarro-García, 2007).

Asimismo, como justicia retributiva, se incluyen las acciones penales, que velarán por la identificación y castigo a los responsables: los juicios a los coroneles griegos, a la Junta Militar argentina, las purgas 0 "lustración" de antiguos colaboradores 0 responsables de las violaciones de los derechos humanos son ejemplos de justicia retributiva o punitiva. Mientras las Comisiones de Verdad se ocupan de la identificación, los tribunales lo harán del castigo a los culpables.

También en ocasiones se han
implementado medidas de justicia
restaurativa, las cuales contemplan
aspectos simbólicos que exigen acciones de


petición de disculpas y de reconocimiento de la responsabilidad por parte de los perpetradores. Buscan, mediante disculpas oficiales, la recuperación del sentido de eficacia y mejora de autoestima de las víctimas $y$, en ocasiones, como en los Gaçaca (juicios populares) de Rwanda, también persiguen que víctimas y victimarios se encuentren, que estos últimos reconozcan sus culpas y se reintegren en la comunidad.

Una de las herramientas para dignificar simbólicamente a las víctimas, suele ser la marcación territorial o temporal de lugares vinculados a la memoria del pasado traumático, alzando símbolos que rememoren a las víctimas y eviten el olvido de lo sucedido, en fechas o lugares que reconstruyen la memoria colectiva de dicho pasado traumático (Jelin, 2002; Jelin y Langland, 2003). Los trabajos de la memoria sirven para transmitir la experiencia a las nuevas generaciones, preservar la memoria colectiva, enriquecer los derechos humanos y el derecho a la identidad, a la libre expresión y a la participación social en decisiones de transcendencia pública.

Finalmente, la justicia distributiva hace referencia a programas de reparación y diversas reformas institucionales que los gobiernos utilizan para reconocer los daños sufridos y tomar medidas para abordarlos. Esas iniciativas suelen tener un componente material (como los pagos monetarios o los servicios sanitarios). Se presupone que el conocimiento de la verdad, la aplicación de la justicia, la petición de disculpas y las acciones de reparación permitirían la reconciliación (Gibson, 2004).

Proceso transicional en Paraguay

Aunque el proceso de transición en el Paraguay se inicia en 1989 con la caída de Stroessner, este se caracterizó por un fuerte pulso entre los sectores democráticos y el atavismo autoritario. El Partido Colorado continuó en el poder hasta el 2008 y solo con el triunfo de Fernando Lugo en la Presidencia de la República, que inició su mandato en agosto de ese año, el país inició su verdadero proceso de transición aunque fue posteriormente alterado por su destitución y la vuelta al poder del mismo Partido Colorado en 2012.

Después de la caída de la dictadura se hicieron pequeños intentos en la reparación hacia las víctimas, pero es la Comisión de Verdad y Justicia (CVJ) uno de los pasos fundamentales en el abordaje del pasado traumático y constituyó un logro de la sociedad civil y del Estado paraguayo. Su creación respondió a la demanda de las asociaciones de víctimas de la dictadura y de los organismos de derechos humanos. Esto se concretó con un acuerdo del Parlamento Nacional y del Poder Ejecutivo, que permitió la sanción de la Ley 2225/03.

Aunque la ley que creó la CVJ fue del 6 octubre de 2003, esta solo se instaló formalmente el 20 de julio de 2004, debido a razones presupuestales. Aunque se preveía inicialmente una duración de dieciocho meses de trabajo, prorrogables a seis meses más, el mandato se extendió por veinticuatro meses más, con diversos periodos de inactividad. La CVJ finalmente entregó su informe el 28 de agosto de 2008.

El mandato de la CVJ estaba centrado en casos de violaciones de derechos humanos, en particular desapariciones forzadas, torturas, exilio y otras graves violaciones ocurridas desde mayo de 1954 hasta octubre de 2003 (mes en que fue promulgada la ley). Sus funciones, establecidas por la ley, fueron las de investigar las violaciones de derechos humanos colaborando con los órganos pertinentes en su esclarecimiento, preservar la memoria y testimonio de las víctimas, procurando determinar el paradero de las personas desaparecidas y tratando de identificar a los responsables de la represión. Asimismo, se esperaba que 
contribuyese al armado de un corpus jurídico de elementos probatorios para que el sistema de justicia actuase sobre los responsables evitando la impunidad, así como que emitiese recomendaciones de reparación y reformas institucionales que evitasen la repetición de los hechos en el futuro.

La CVJ organizó seis audiencias públicas nacionales y dos internacionales. Las tres primeras audiencias nacionales se realizaron en las ciudades de Asunción, San Juan Bautista de Misiones y Caaguazú, respectivamente, con el propósito de escuchar a las víctimas de la dictadura. Las audiencias internacionales se desarrollaron en las ciudades argentinas de Buenos Aires, para dignificar a los miles de paraguayos exiliados en ese país, y en Posadas para documentar el exilio paraguayo en la frontera argentina. Las dos últimas audiencias fueron temáticas y se realizaron en Asunción, sobre "mujeres, niños y niñas en la dictadura stronista" y sobre "pueblos indígenas y dictadura".

La CVJ estableció la responsabilidad del Estado en estas violaciones de derechos humanos, en particular del Poder Ejecutivo, ejercido en forma unipersonal por el Presidente de la República, de la Policía Nacional y de las Fuerzas Armadas de la Nación, así como en general de la administración pública. También, estableció la responsabilidad del Poder Legislativo, de la entonces Junta Electoral Central y del Poder Judicial, en particular de la Corte Suprema de Justicia. De manera especial, se subrayaron las responsabilidades personales de Alfredo Stroessner, de los miembros de las Fuerzas Policiales, de los miembros de las Fuerzas Armadas, de los ministros responsables de entes y empresas del Estado, y otros funcionarios públicos. Así también, de algunos parlamentarios, integrantes de la Corte Suprema de Justicia, jueces de primera instancia y miembros de tribunales de apelación.
La CVJ también señaló que fue responsable por las violaciones de derechos humanos ocurridas la Asociación Nacional Republicana (Partido Colorado), con las excepciones del Movimiento Popular Colorado (Mopoco) y de la Asociación Nacional Republicana del Exilio y la Resistencia (ANRER), por su disidencia y resistencia a la dictadura. Del mismo modo, fueron responsables los particulares que actuaron con el apoyo y la tolerancia de agentes del Estado y de su partido, especialmente dirigentes de las seccionales coloradas, milicias, guardias urbanas 0 militantes que participaron con 0 sin uniforme, policial o militar. También hubo responsabilidad, en la actitud personal e institucional, de algunos empresarios privados y de gremios empresariales, de algunos medios de prensa, en particular la prensa del partido oficialista, de la jerarquía de la Iglesia Católica, especialmente en la primera década del sistema dictatorial, y de miembros de otros grupos religiosos.

Asimismo, indicó la responsabilidad de algunas administraciones gubernamentales de los Estados Unidos de América, de algunos Gobiernos del Estado brasileño y de la cooperación de los sistemas represivos vinculados con la Operación Cóndor (promovida por los Gobiernos de las dictaduras militares de Argentina, Uruguay y de Augusto Pinochet en Chile) en las violaciones de derechos humanos ocurridas durante la dictadura de Stroessner. Durante la presentación del informe elaborado por la CVJ, el Presidente de la Republica Sr. Lugo pidió perdón en nombre de la Nación por el dolor causado a las víctimas, por la soledad a la que fueron sometidos los perseguidos.

A estas medidas restaurativas, también prosiguieron medidas simbólicas como la apertura del Museo Virtual en la Web MEVES: Memoria y Verdad sobre el Stronismo, que compila la historia, testimonios y documentos sobre el régimen de Alfredo Stroessner, ofreciendo testimonios, imágenes, vídeos, audio y 
recuerdos que ilustran la verdad histórica del pasado reciente. Esta propuesta se suma al Museo de la Justicia, Centro de Documentación y Archivo para la Defensa de los Derechos Humanos del Poder Judicial, que alberga los denominados Archivos del Terror, expedientes policiales del régimen stronista hallados el 22 de diciembre de 1992, así como el Museo de la Memoria de Asunción, que tiene como sede a una antigua dependencia policial donde se torturaba a los perseguidos políticos durante ese período.

Para la búsqueda de los desaparecidos se organizó una Unidad de Desapariciones Forzadas y Ejecuciones Extrajudiciales, que trabajó con el listado de las personas desaparecidas y ejecutadas extrajudicialmente de la CVJ y realizó la búsqueda de desaparecidos en tumbas N.N., en fosas y otros lugares en los que se podrían encontrar enterradas las posibles víctimas de desaparición forzada. La propia CVJ, con la colaboración del Equipo Argentino de Antropología Forense y el director de Reparación y Memoria Histórica de Paraguay, Rogelio Goiburú, emprendió durante su periodo de mandato un total de seis excavaciones, donde se hallaron restos pendientes de estudios periciales relativos a investigación y comparación genética. Asimismo, se participó en otras realizadas en territorio argentino donde desaparecieran otros ciudadanos paraguayos.

Finalmente, el Estado paraguayo concedió algunas indemnizaciones parciales a víctimas de la dictadura con anterioridad al trabajo de la Comisión, pero la CVJ estableció entre sus recomendaciones la necesidad de complementar dichas indemnizaciones, y crear una Secretaria de Derechos Humanos que llevase a cabo las recomendaciones de la CVJ.

No se han realizado medidas de justicia distributiva: no se han realizado juicios penales y no hay sentencias ni condenas contra quienes participaron en las violaciones de derechos humanos, más allá del inicio de algunos procesos que finalmente fueron truncados, y de la condena de la Corte Interamericana de Derechos Humanos al Estado paraguayo por la detención y desaparición forzada de Agustín Goiburu, los hermanos Ramírez Villalba y Amilcar Oviedo, primera sentencia dada en el marco de la operación cóndor.

\section{Las víctimas luego de la represión}

Las violaciones de derechos humanos, como la represión política como la vivida en Paraguay, suelen dejar un fuerte impacto emocional y social en las comunidades que lo enfrentan. En ocasiones, ese impacto, puede leerse en términos de desafección política, de desinterés 0 de una desmovilización social como reacción a la amenaza política y al miedo (Lira, 1991). Incluso se ha encontrado que, aunque entre las víctimas suele haber más necesidad de hablar y compartir socialmente sobre los hechos de la violencia, esta necesidad convive con la inhibición de ciertos aspectos sobre los que se prefiere no hablar (Cárdenas, et. al., 2013).

Sin embargo, a pesar de estas cuestiones, a menudo las víctimas son las que se organizan para reclamar medidas de reparación, de verdad y justicia como las descritas anteriormente, y en algunas ocasiones, esta movilización, suele ser casi exclusiva de los colectivos afectados, como se muestra en un estudio anterior realizado en Argentina, donde la población no afectada, a penas de movilizaba en las acciones de los colectivos de víctimas o sobrevivientes (Arnoso, 2012). En realidad, las actitudes y opiniones de la población ante las medidas que se implementan en relación al pasado represivo suele ser diversa, dependiendo, entre otras cuestiones, del nivel de exposición de la población a la violencia o la cercanía percibida con las víctimas. En Guatemala, el $74 \%$ de la población creía que era importante conocer la verdad de lo que les 
ocurrió a los desaparecidos y asesinados en los años de la guerra, de forma significativa entre la población con un mayor nivel de exposición a la violencia (Navarro et al, 2009). En el caso que nos ocupa, el Movimiento de Víctimas de la Dictadura y la Agrupación de Familiares de Detenidos Desaparecidos y Asesinados del Paraguay (FADDAPY), han sido las más movilizada a ese nivel. La lucha contra el olvido y la conmemoración testimonial, son mecanismos que permiten darle un sentido social a las memorias individuales intrusivas de hechos traumáticos colectivos.

El hecho de dar su testimonio puede no tener un efecto positivo sobre las víctimas. Más bien, se ha encontrado que presentar testimonio ante CV puede producir un alto costo emocional para las víctimas, aumentando las emociones negativas, los niveles de depresión e incluso en ocasiones la reaparición de sintomatología postraumática cuando estas expresiones no van acompañadas de la certidumbre sobre la aplicación de justicia o medidas de reparación adecuadas (Brounéus, 2008; Kaminer et al, 2001; Hamber, 2007; Rimé et al, 2011). Estudios previos nos informan de que las emociones evocadas luego de las Comisiones de la Verdad son más intensas entre las víctimas directas, tanto las positivas como las negativas, confirmando el impacto emocional que estas medidas tienen sobre todo sobre la población afectada (Cárdenas, et. al., 2013). Pese al coste emocional de las declaraciones, las víctimas también pueden experimentar orgullo, alivio y la sensación de realización por haber tenido la oportunidad de expresar públicamente y oficialmente su experiencia (Kanyangara et al, 2007; Kanyangara, 2008). Igualmente, se ha detectado que en los países en que se han desarrollado CV cuyo trabajo es valorado positivamente por la población, existe una mejora en la situación política (Sikkink \& Booth-Walling, 2007) y una mayor valoración de los derechos humanos (Pérez-Sales et al, 2009; Beristain et al., 2010), así como mayores niveles de confianza institucional (Bar-Tal, 2011; Cárdenas et al, 2013). Además, si las víctimas reciben disculpas y se les repara en algún sentido, se sentirán más proclives a plantear reivindicaciones, aumentando su sentido de ciudadanía (Beristain et al, 2010), toda vez que logran articular sentido vital desde las demandas de verdad y justicia (Cárdenas et al, 2013). Lo que la violencia hizo fue coartar a las víctimas en tanto que sujetos políticos, privándolos de participar en los asuntos del ámbito público. De allí que el trabajo de las CV sirva para reinsertar a dicho grupo en el ámbito de relaciones del cual fue violentamente despojado, generando una sensación de mayor eficacia colectiva (Lykes, Beristain y Cabrera, 2007).

Las CV se constituyen como una plataforma que permite el encuentro entre quienes se mantenían en disputa, promoviendo un mayor contacto positivo y un refuerzo de la igualdad (Nadler, Malloy \& Fisher, 2008). Las CV, en tanto ritual transicional en que la institucionalidad reconoce públicamente la violación de una norma y ofrece disculpas y reparación por ello, permiten restaurar la armonía perdida y alcanzar la cohesión social en la medida en que reafirma las normas y valores de la comunidad (Tavuchis, 1991). En los contextos en que se hace saliente la petición de disculpas se observa una mejora en el clima emocional (Bobowik, Bilbao y Momoitio, 2010) que incluye la percepción de solidaridad y confianza social (Valencia, Momoitio y Idoyaga, 2010), aunque no necesariamente eso conlleve a alcanzar la reconciliación. Este suele ser un objetivo más deseado por las personas que de alguna manera muestran una mayor afinidad ideológica con los responsables de la violencia (Arnoso, 2012).

\section{Sobre el presente estudio}

El presente artículo describe el impacto de las violaciones a los derechos humanos en la población paraguaya de las regiones más 
represaliadas del interior rural del país (Misiones y Caaguazú). En particular, indagamos en la necesidad de compartir socialmente acerca de los hechos y el impacto emocional asociado al recuerdo del pasado traumático. Igualmente, se analiza el conocimiento de las medidas de justicia transicional implementadas (CVJ, exhumaciones, peticiones de perdón, museos) y la valoración o percepción de eficacia del trabajo realizado por la comisión de Verdad y Justicia y la peticiones de perdón emitidas por el presidente Lugo después de la presentación del Informe de la CVJ, así como la deseabilidad social y condiciones necesarias para alcanzar la reconciliación. Asimismo, se explora la participación de la población en movilizaciones 0 acciones colectivas de derechos humanos vinculadas a la denuncia del pasado represivo, explorando las diferencias en función del grado de exposición a la violencia de la población entrevistada. Finalmente, se analiza la percepción del clima emocional actual, la confianza institucional y su relación con las variables analizadas.

\section{METODO}

Muestra

La muestra quedó compuesta por 400 personas (200 en el departamento de Misiones y 200 en Caaguazú), de las cuales el $52 \%$ eran hombres y el $48 \%$ mujeres, con una edad comprendida entre los 18 y los 90 años $(M=40.39 ; \quad D T .=16.90)$. Un $35.5 \%$ $(n=152)$ se declaró víctima directa de las violaciones ocurridas durante la dictadura; un $56.8 \%(n=227)$ víctima indirecta y solo un $7.8 \%(n=31)$ expresó que ni ella ni ninguna persona de su familia había sido afectada por la represión. Una amplia mayoría se define de izquierdas $(77,8 \% ; n=311)$ y un $22,3 \% \quad(n=89)$ se situaría en el centro del espectro ideológico. Ninguna persona se definió de derechas. En cuanto al origen étnico, el $73 \%$ se define como mestizo, un $24.5 \%$ blanco, un $2.3 \%$ afroamericano y sólo una persona se definió como perteneciente a los pueblos originarios.

Instrumento y variables

Se administró un cuestionario que indagaba en las características socio-demográficas de la muestra: sexo, edad, nivel de exposición a la violencia (victima directa, víctima indirecta o familiar de víctima directa y no afectada), ideología (izquierda, centro o derecha) y pertenencia étnica (pregunta abierta posteriormente recodificada). En el segundo bloque se consultó sobre las siguientes variables:

Violación de derechos humanos. Se estableció un listado con las violaciones más frecuentes solicitando a la población entrevistada que contestase cuáles de estas violaciones habían sufrido ellas mismas 0 sus familiares (indicando en ese caso el vínculo familiar que tenían con ellas).

Compartir social. Se incluyeron 3 ítems ("grado de necesidad de hablar sobre la dictadura", "existencia de aspectos no hablados" y "existencia de aspectos de los que no desea hablar"), todos ellos con un formato de respuesta en escala Likert de cuatro opciones de respuesta ( $1=$ "Nada" y 4 = "Mucho").

Emociones vinculadas al recuerdo del pasado represivo. Se entregó un listado de 5 emociones negativas y 1 positiva (tristeza, culpa, ira, miedo, vergüenza y alegría), con una escala con siete opciones de respuesta (1 = "En absoluto" y 7 = "Totalmente").

Conocimiento de las medidas transicionales. Se entregó un listado con las medidas realizadas para que indicaran cuáles conocían. Se incluyó la CVJ, disculpas oficiales, exhumaciones, museos y archivo. La opción de respuesta fue de carácter dicotómico (respuesta SI/NO).

Participación en audiencias. Se consultó a las víctimas directas e indirectas si habían participado en las audiencias públicas de la 
CVJ y si su testimonio había quedado reflejado en el informe. El formato de respuesta fue dicotómico (SI/NO).

Valoración de la eficacia de la CVJ. Se indagó sobre el cumplimiento de las metas en lo referido a: a) ayudar a que las familias supiesen la verdad de lo ocurrido con sus familiares; b) crear una historia integradora para todas las partes implicadas, c) contribuir a juzgar a los responsables de la violencia colectiva y d) evitar que las violaciones a los derechos humanos vuelvan a ocurrir en el futuro. Se recurrió a escala tipo Likert con cuatro opciones de respuesta, donde 1 = "En absoluto" y 4 = "Totalmente".

Perdón y disculpas. Se consultó, en qué medida consideraban que las víctimas podían perdonar a los victimarios, si las declaraciones y disculpas habían sido sinceras, habían servido para ayudar a la sociedad a comprender el sufrimiento de los afectados y habían contribuido a mejorar la relación y promover la confianza entre los diferentes grupos en conflicto. Se utilizó una escala en formato Likert con cuatro opciones de respuesta (1 = "En absoluto" y 4 = "Totalmente").

Reconciliación. Se consultó sobre la deseabilidad de la reconciliación mediante una pregunta directa y se pidió una valoración de 6 requisitos previos para que esta pueda producirse $(1=$ "Nada" y $7=$ "Muchísimo").

Impacto en la participación política. Para medir el impacto psicosocial de la dictadura en términos de participación social o política se incluyeron 4 ítems que preguntaban sobre si la dictadura había motivado desafección y/o interés por la política (1 = "En absoluto" y 7 = "Totalmente") y si se participaba actualmente en actividades de organizaciones de derechos humanos 0 actividades organizadas por las víctimas de la dictadura (1 = "Nada" y 4 = "Mucho").
Confianza institucional. Se pasó un listado de 11 ítems para medir la confianza en distintas instituciones del país con un formato de respuesta tipo Likert ( 1 = "en absoluto" y 7 = "Totalmente").

Clima social (Páez et al., 1997). Escala de cuatro preguntas en una escala tipo Likert con cinco opciones de respuesta, donde 1= "En absoluto" y 5 = "Totalmente". En conjunto los ítems evalúan la percepción del clima social positivo de solidaridad, ayuda mutua y de confianza en las instituciones, así como negativo con predominio del enojo y la hostilidad entre las personas y grupos, así como un bajo estado de ánimo caracterizado por la tristeza y la pasividad.

\section{Procedimiento}

Los cuestionarios fueron administrados por encuestadores/as locales que previamente fueron formados por el coordinador responsable. Antes de la pasación del cuestionario, las personas firmaron un consentimiento previo donde se les informaba de los objetivos de la investigación y el anonimato de sus respuestas.

\section{RESULTADOS}

\section{Las violaciones a los derechos humanos}

El $35.5 \%(n=142)$ de las personas entrevistadas se definen a sí mismas como víctimas del Estado en relación al periodo represivo (1970-1983). Hay una mayoría de hombres $(52.1 \% ; n=74)$ que de mujeres $(47.9 \% ; n=68)$ en este colectivo, con una edad media de 55.17 años. Las violaciones que en mayor medida describen estas personas son torturas $(89.4 \% ; n=127)$ y/o prisión $(35.2 \% ; n=59)$, aunque también se registraron otras violaciones como exilio $(9.2 \% ; n=13)$, pérdida de tierras $(7.7 \% ; n=$ 11) o destitución del empleo o cargo que desempeñaban $(4.2 \% ; n=6)$. 
Por otro lado, un $80.8 \%(n=323)$ de las personas entrevistadas expresaron que familiares suyos habrían sido víctimas de las violaciones a los derechos humanos perpetradas durante el periodo dictatorial. Analizando los vínculos con estas personas encontramos que se tratan principalmente de sus padres o madres $(51.1 \% ; n=165)$, abuelos/as (31.3\%; $n=101)$ o hermanos/as $(21.4 \% ; n=69)$. Asimismo, un $13.9 \%$ ( $n=$ 45) hizo referencia a sus parejas y un porcentaje similar $(13.3 \% ; n=43)$ a sus hijos/as. Con cifras menores, se citó también a familiares de segunda línea como tíos/as (7.7\%; $n=25)$, sobrinos/as (5.9\%; $n$ $=19)$, primos/as (5.6\%; $n=18)$ o amigos/as $(1.5 \% ; n=5)$. Las violaciones que sufrieron sus familiares se refieren fundamentalmente a torturas (85.1\%; $n=275)$, prisión (31\%; $n$ $=100$ ), desaparición forzada y ejecuciones extrajudiciales (19.5\%; $n=63)$, pérdida de tierras $(13.6 \% ; n=44)$, exilio $(13.3 \% ; n=$ 43) y pérdida de trabajo o empleo $(8.4 \% ; n$ $=27$ ).

Solo 31 personas $(7.8 \%)$ de la muestra, no se consideraron víctimas directas 0 indirectas del pasado represivo.
Compartir social sobre el pasado y emociones asociadas por nivel de exposición a la violencia colectiva

La necesidad de hablar, de compartir social sobre lo ocurrido durante los años de la dictadura es bastante 0 muy alta, independientemente del nivel de exposición a la violencia de las personas entrevistadas. Sin embargo, esta necesidad de hablar se combina con un alto grado de aspectos que nunca se han hablado con nadie y la existencia de algunas cuestiones de las que no se quiere ni hablar, especialmente cuanto más directa ha sido la violencia ejercida sobre las personas entrevistadas (ver Tabla 1).

Su recuerdo se asocia principalmente con emociones de tristeza e ira, independientemente del nivel de exposición a la violencia y se rechazan las emociones de alegría, vergüenza, culpa o miedo, aunque tanto la culpa como la vergüenza, están ligeramente más presentes entre las víctimas directas (ver Tabla 1).

TABLA 1.

Compartir social, emociones, eficacia percibida en CVJ, disculpas y perdón: medias y desviaciones típicas por exposición a la violencia.

\begin{tabular}{|c|c|c|c|c|c|c|c|c|c|c|}
\hline & \multicolumn{2}{|c|}{$\begin{array}{l}\text { VÍCTIMA } \\
\text { DIRECTA }\end{array}$} & \multicolumn{2}{|c|}{$\begin{array}{c}\text { VÍCTIMA } \\
\text { INDIRECTA }\end{array}$} & \multicolumn{2}{|c|}{ NO AFECTADO } & \multicolumn{2}{|c|}{ TOTAL } & \multicolumn{2}{|c|}{$\begin{array}{c}\text { DIF. } \\
\text { GLOBALES }\end{array}$} \\
\hline & $\mathrm{M}$ & DT & M & DT & M & DT & M & DT & $\mathrm{F}$ & Sig. \\
\hline \multicolumn{11}{|c|}{ COMPARTIR SOCIAL Y EMOCIONES ASOCIADAS } \\
\hline Necesidad de hablar & 3.73 & 3.44 & 3.55 & 0.51 & 3.48 & 0.51 & 3.61 & 2.09 & .405 & .667 \\
\hline Aspectos no hablados & 3.46 & 0.50 & 3.47 & 0.50 & 3.35 & 0.49 & 3.46 & 0.50 & 692 & .501 \\
\hline No se desea hablar & 3.58 & 0.50 & 3.41 & 0.57 & 3.35 & 0.61 & 3.47 & 0.55 & 4.607 & .011 \\
\hline Tristeza & 6.22 & 0.60 & 6.30 & 0.62 & 6.26 & 0.58 & 6.27 & 0.61 & .865 & .422 \\
\hline Culpa & 3.30 & 0.58 & 2.95 & 0.96 & 2.52 & 1.12 & 3.04 & 0.89 & 13.638 & .000 \\
\hline Ira & 6.30 & 0.59 & 6.30 & 0.59 & 6.39 & 0.62 & 6.31 & 0.59 & .326 & .722 \\
\hline Miedo & 3.44 & 0.50 & 3.46 & 0.61 & 3.26 & 0.63 & 3.44 & 0.58 & 1.663 & .191 \\
\hline Vergüenza & 1.92 & 1.03 & 1.63 & 0.65 & 1.84 & 0.64 & 1.75 & 0.81 & 5.519 & .004 \\
\hline Alegría & 1.73 & 2.49 & 1.49 & 0.54 & 1.55 & 0.57 & 1.58 & 1.54 & 1.055 & .349 \\
\hline \multicolumn{11}{|l|}{ EFICACIA PERCIBIDA EN CVJ } \\
\hline Ayuda a las familias & 3.50 & 0.57 & 3.52 & 0.52 & 3.52 & 0.51 & 3.51 & 0.53 & .061 & .941 \\
\hline Versión confiable & 3.46 & 0.50 & 3.30 & 0.66 & 3.35 & 0.61 & 3.36 & 0.61 & 3.244 & .040 \\
\hline Historia integradora & 3.43 & 0.59 & 3.48 & 0.52 & 3.48 & 0.51 & 3.47 & 0.54 & .468 & .627 \\
\hline Juzgar responsables & 3.44 & 0.50 & 3.51 & 0.51 & 3.23 & 0.50 & 3.47 & 0.51 & 4.549 & .011 \\
\hline No repetición & 3.39 & 0.52 & 3.49 & 0.53 & 3.48 & 0.51 & 3.46 & 0.52 & 1.484 & .228 \\
\hline Eficacia Media & 3.45 & 0.25 & 3.46 & 0.25 & 3.41 & 0.25 & 3.45 & 0.25 & .566 & .568 \\
\hline \multicolumn{11}{|l|}{ DISCULPAS Y PERDÓN } \\
\hline Sinceridad disculpas & 3.33 & 0.56 & 3.31 & 0.54 & 3.48 & 0.63 & 3.33 & 0.55 & 1.372 & .255 \\
\hline Entender sufrimiento & 3.11 & 0.63 & 3.28 & 0.57 & 3.26 & 0.58 & 3.22 & 0.60 & 3.826 & .023 \\
\hline confianza intergrupal & 2.77 & 0.77 & 3.26 & 0.60 & 3.26 & 0.73 & 3.09 & 0.71 & 24.030 & .000 \\
\hline ¿Pueden las víctimas perdonar? & 1.88 & 0.71 & 1.70 & 0.63 & 1.61 & 0.56 & 1.76 & 0.66 & 4.121 & .017 \\
\hline
\end{tabular}


La población ante el perdón y la reconciliación

La sinceridad percibida en las disculpas púbicas pronunciadas por el ex presidente Lugo es alta, y esta percepción es compartida por los diferentes grupos entrevistados independientemente de cuanto de afectados fueron por la represión. En esa misma línea, también se percibe una alta eficacia, tanto para que la sociedad comprendiese el sufrimiento de las víctimas como para mejorar la confianza y las relaciones intergrupales. Eso sí, en relación a la eficacia, la percepción desciende entre las víctimas directas en comparación con el subconjunto homogéneo que conforman las víctimas directas y la población no afectada (ver Tabla 1).

Aun cuando la posibilidad de perdonar es baja en todos los grupos, son las víctimas directas las que más proclives se mostrarían para ello, en comparación con lo expuesto por las víctimas indirectas o la población no afectada (ver Tabla 1).
La reconciliación es un objetivo muy deseado por la población, especialmente para las víctimas indirectas y la población no afectada. Entre los requisitos para que ésta pueda alcanzarse destaca: que no se olvide y que haya memoria del pasado traumático, que haya nuevas generaciones que no hayan vivido dicho periodo, la necesidad de que haya justicia y castigo para los responsables de las violaciones, que se resuelva lo que dio lugar al conflicto o que los responsables pidan perdón. Se rechaza la exigencia de que las víctimas tengan que perdonar a los victimarios, aunque las víctimas directas sean nuevamente las que puntuarían de forma ligeramente más alto en esta cuestión. En el resto de los requisitos, no se han encontrado diferencias significativas entre los grupos, mostrando un alto grado de consenso en aquello que se considera importante para avanzar en la reconciliación social o nacional (ver Tabla 2).

TABLA 2.

Reconciliación, impacto, participación social y clima emocional: medias y desviaciones típicas por exposición a la violencia.

\begin{tabular}{|c|c|c|c|c|c|c|c|c|c|c|}
\hline & \multicolumn{2}{|c|}{ VÍCTIMA DIRECTA } & \multicolumn{2}{|c|}{ VÍCTIMA INDIRECTA } & \multicolumn{2}{|c|}{ NO AFECTADO } & \multicolumn{2}{|c|}{ TOTAL } & \multicolumn{2}{|c|}{ DIF. GLOBALES } \\
\hline & $M$ & DT & $\mathrm{M}$ & DT & $\mathrm{M}$ & DT & $\mathrm{M}$ & DT & $\mathrm{F}$ & Sig. \\
\hline \multicolumn{11}{|l|}{ RECONCILIACION } \\
\hline Deseabilidad & 6.13 & 0.84 & 6.33 & 0.55 & 6.29 & 0.69 & 6.26 & 0.68 & 3.551 & .030 \\
\hline Que las victimas perdonen & 1.10 & 0.30 & 1.00 & 0.00 & 1.00 & 0.00 & 1.04 & 0.18 & 14.004 & .000 \\
\hline Peticiones perdón & 6.29 & 0.55 & 6.42 & 0.50 & 6.39 & 0.56 & 6.37 & 0.52 & 2.906 & .056 \\
\hline Memoria. no olvido & 6.45 & 0.60 & 6.57 & 0.50 & 6.61 & 0.50 & 6.53 & 0.54 & 2.640 & .073 \\
\hline Juicio y castigo & 6.64 & 0.56 & 6.60 & 0.51 & 6.48 & 0.51 & 6.61 & 0.53 & 1.139 & .321 \\
\hline Nuevas generaciones & 6.56 & 0.59 & 6.58 & 0.50 & 6.58 & 0.50 & 6.57 & 0.53 & .033 & .967 \\
\hline Resolver conflicto & 6.37 & 0.57 & 6.41 & 0.49 & 6.42 & 0.50 & 6.40 & 0.52 & .244 & .784 \\
\hline \multicolumn{11}{|l|}{ IMPACTO Y PARTICIPACIÓN SOCIAL } \\
\hline Participación derechos humanos & 3.39 & 0.52 & 3.30 & 0.56 & 3.32 & 0.54 & 3.33 & 0.55 & 1.453 & .235 \\
\hline Participación actividades de víctimas & 3.57 & 0.56 & 3.56 & 0.51 & 3.48 & 0.63 & 3.56 & 0.54 & .339 & .644 \\
\hline Desafección política & 1.63 & 0.54 & 1.94 & 0.62 & 1.97 & 0.55 & 1.84 & 0.60 & 13.015 & .000 \\
\hline Interés político & 6.49 & 0.64 & 6.12 & 0.83 & 5.81 & 0.87 & 6.23 & 0.80 & 14.840 & .000 \\
\hline \multicolumn{11}{|l|}{ CLIMA EMOCIONAL } \\
\hline Solidario & 3.23 & .68 & 3.42 & .61 & 3.45 & .72 & 3.36 & .65 & 3.893 & .021 \\
\hline Confianza instituciones & 1.60 & 0.67 & 1.70 & 0.62 & 1.45 & 0.51 & 1.64 & 0.63 & 2.804 & .062 \\
\hline Hostilidad & 3.40 & 0.62 & 3.52 & 0.54 & 3.39 & 0.56 & 3.47 & 0.57 & 2.110 & .123 \\
\hline Tristeza y pasividad & 3.16 & 0.76 & 3.20 & 0.69 & 3.03 & 0.91 & 3.17 & 0.73 & .720 & .487 \\
\hline Media clima positivo & 2.41 & 0.47 & 2.56 & 0.45 & 2.45 & 0.51 & 2.50 & 0.47 & 4.439 & .012 \\
\hline Media clima negativo & 3.28 & 0.48 & 3.36 & 0.44 & 3.21 & 0.57 & 3.32 & 0.46 & 2.116 & .122 \\
\hline
\end{tabular}


Impacto psicosocial de la dictadura sobre la participación social y/o política

La dictadura no consiguió descender el interés de la población por cuestiones sociales o políticas, y mucho menos lo logró entre las víctimas directas. A la inversa, la población expresa que en todo caso aumentó su interés por estas cuestiones y cuanto mayor es el nivel de represión soportado, mayor es este aumento (ver Tabla 2).

El grado de participación en actividades de derechos humanos 0 en acciones organizadas por los familiares de afectados es alto, y no difiere en función del nivel de exposición a la violencia (ver Tabla 2).

\section{Clima emocional}

Predomina un clima emocional negativo, de falta de confianza en las instituciones, de percepción de agresividad entre las personas y de tristeza que contrasta con una mayor percepción de solidaridad y ayuda mutua a nivel comunitario. Esta percepción de solidaridad es mayor entre los no afectados y las víctimas indirectas en comparación con las directas quienes en general son quienes en menor medida perciben un clima emocional positivo. En el resto de las dimensiones no se encontraron diferencias significativas a ese nivel (ver Tabla 2).

Conocimiento de las medidas transicionales y exposición violencia colectiva

En general, la población tiene un amplio conocimiento respecto a las medidas que se han implementado en relación al pasado: prácticamente la totalidad de las personas entrevistadas conocen la Comisión Verdad y Justicia, conocen las disculpas emitidas por el presidente Lugo, la totalidad sabe que se han realizado excavaciones para proceder a la exhumación e identificación de cadáveres de personas detenidas y/o ejecutadas extrajudicialmente, conocen la existencia de los Archivos del Horror, y aunque en menor medida, también una amplia mayoría tiene conocimiento de la existencia de un Museo de la Memoria en la capital del país. Sin embargo, sólo cuatro personas conocen la existencia de un museo virtual (ver Tabla 3).

No existen diferencias significativas en función del nivel de exposición a la represión de la población entrevistada, a excepción de lo relativo al Museo de la Memoria y los Archivos del Horror, siendo las víctimas directas quienes en mayor medida conocen estas marcaciones mnésicas (ver Tabla 3).

TABLA 3.

Participación y conocimiento de las medidas implementadas por nivel de exposición a la violencia: frecuencias y porcentajes.

\begin{tabular}{|c|c|c|c|c|c|c|c|c|c|}
\hline & \multicolumn{2}{|c|}{ VÍCTIMA DIRECTA } & \multicolumn{2}{|c|}{$\begin{array}{c}\text { VÍCTIMA } \\
\text { INDIRECTA }\end{array}$} & \multicolumn{2}{|c|}{ NO AFECTADO } & \multicolumn{2}{|c|}{ TOTAL } & \multirow[b]{2}{*}{$\mathrm{X}^{2}$} \\
\hline & $\mathrm{n}$ & $\%$ & $n$ & $\%$ & $\mathrm{n}$ & $\%$ & $n$ & $\%$ & \\
\hline Información CVJ & 142 & $100 \%$ & 222 & $97.8 \%$ & 30 & $96.8 \%$ & 394 & $98.5 \%$ & 3.52 . \\
\hline Participación CVJ & 137 & $96.5 \%$ & 206 & $90.7 \%$ & - & - & 343 & $93 \%$ & $4.37^{*}$ \\
\hline ¿Testimonio CVJ? & 137 & $96.5 \%$ & 205 & $90.3 \%$ & - & - & 342 & $92.7 \%$ & $4.90^{\star}$ \\
\hline Conoce Disculpas & 141 & $99.3 \%$ & 227 & $100.0 \%$ & 31 & $100.0 \%$ & 399 & $99.8 \%$ & 1.82 \\
\hline Excavaciones & 142 & $100.0 \%$ & 227 & $100.0 \%$ & 31 & $100.0 \%$ & 400 & $100.0 \%$ & - \\
\hline Museo Memoria & 137 & $96.5 \%$ & 147 & $64.8 \%$ & 24 & $77.4 \%$ & 308 & $77.0 \%$ & $49.63^{* *}$ \\
\hline Archivos Horror & 142 & $100.0 \%$ & 208 & $92.0 \%$ & 30 & $96.8 \%$ & 380 & $95.2 \%$ & $12.37^{* *}$ \\
\hline Museo Virtual & 0 & $.0 \%$ & 4 & $1.8 \%$ & 0 & $.0 \%$ & 4 & $1.0 \%$ & 3.07 \\
\hline
\end{tabular}


Participación en la CVJ y eficacia percibida

Del total de las víctimas (directas 0 indirectas) entrevistadas, una amplia mayoría reconoció haber prestado su testimonio para la Comisión de Verdad y Justicia $\mathrm{y}$, además, perciben que lo que contaron quedó registrado en el informe final. Especialmente así lo creen aquellas con una afectación más directa (ver Tabla 3).

En cuanto a la percepción de eficacia del trabajo de la CVJ, la población entrevistada opina que sobre todo fueron útiles para ayudar a las familias de las víctimas, construir una historia integradora, ayudar a juzgar a los responsables (de forma significativa las victimas indirectas), evitar que los hechos puedan volver a repetirse y a construir una versión confiable de la historia (de forma significativa las víctimas directas en comparación con los otros grupos). En conjunto, la eficacia media percibida es alta, de forma compartida por todos los grupos independientemente del nivel de exposición a la violencia de la población entrevistada (ver Tabla 1).

\section{Correlación entre variables}

El análisis de correlaciones de $r$ de Pearson mostró la existencia de aspectos no hablados sobre la dictadura se asocia a más emociones de culpa $(r=.13)$ e ira $(r=.18)$, mientras que el deseo de no hablar sobre determinados aspectos de la violencia se relaciona con menos ira $(r=-.10)$, menos miedo( $r=-.16)$, menor percepción de eficacia de la CVJ ( $r=-.14)$ y mayor grado de exposición a la violencia $(r=-.14)$

Por otra parte, haber prestado su testimonio en la CVJ se asociaba con mayor nivel de exposición a la violencia $(r=-.13)$, más emociones de tristeza $(r=.17)$ y culpa $(r=.14)$, aunque también con una menor desafección social o política $(r=-.19)$ y un mayor conocimiento del trabajo realizado por la CVJ $(r=.19)$.
Un mayor conocimiento de las medidas transicionales se asociaba a un mayor nivel de exposición a la violencia $(r=-.26)$, a una percepción menor del clima social positivo $(r$ $=-.14$ ), a una menor eficacia de las disculpas oficiales $(r=.11)$, a un menor descenso del interés político $(r=-.16)$ y a un aumento del interés por cuestiones sociales o políticas $(r=.23)$.

La eficacia percibida en la CVJ se asoció a más emociones de miedo $(r=.14)$, culpa $(r=.10)$ y a menor inhibición en el reparto social sobre la dictadura $(r=-.14)$.

Por su parte, la eficacia percibida en las disculpas se asoció a una mayor deseabilidad de la reconciliación $(r=.38)$, a una mayor desafección política $(r=.17)$, a una menor necesidad de hablar sobre la dictadura $(r=-.16)$, a un menor nivel de exposición a la violencia ( $r=.26)$, a un menor conocimiento medio de las medidas transicionales implementadas $(r=-.11)$ y a una menor participación en actividades realizadas por los organismos de derechos humanos $(r=-.15)$.

La deseabilidad de la reconciliación a su vez se asocia con un menor clima social negativo $(r=-.11)$, mayor conocimiento $(r=$ $.39)$, sinceridad ( $r=.22$ ) y eficacia percibida en las disculpas de Lugo $(r=.38)$, mayor desafección política $(r=.13)$ y menor participación en organizaciones de afectados $(r=-.11)$.

El aumento del interés por cuestiones sociales o políticas se relaciona con un mayor nivel de exposición a la violencia $(r=$ $-.26)$, más emociones de culpa $(r=.17)$, más conocimiento de las medidas transicionales $(r=.23)$ y un menor clima social positivo percibido $(r=-.12)$.

\section{DISCUSION}

Tal como reflejó el Informe de la Comisión de Verdad y Justicia, la extensión de la violencia en las zonas rurales de Paraguay 
fue mayor que en otras regiones urbanas del país y prácticamente la totalidad de la población sufrió, de manera directa 0 indirecta, las violaciones a los derechos humanos ejercidas durante el periodo de Stroessner, especialmente la tortura y la prisión. Hay que tener en cuenta que la población media del Paraguay, en el periodo estudiado, era de dos millones y medio de habitantes, lo que muestra el alto nivel de impacto producido. A diferencia de lo ocurrido en otros países del Cono Sur, sobre todo allí donde la represión fue fundamentalmente urbana, la apropiación de tierras también constituyó una violación que afectó a una parte de la población rural paraguaya. Así lo señalaba también el informe de la CVJ, quien examinó las adjudicaciones de tierra rural y los títulos de propiedad respectivos otorgados por los organismos estatales responsables de la reforma agraria, desde 1954-1989 y de 1989-2003, a fin de determinar si las adjudicaciones y el otorgamiento de los títulos de propiedad se habían hecho conforme a las leyes que rigen la materia y si habían reunido los presupuestos legales requeridos vigentes en el momento de las concesiones de referencia, encontrando serias irregularidades en la adjudicación que las tornan nulas. Recomendó que el Estado promoviera las acciones pertinentes ante la justicia, y la reparación de los daños y perjuicios causados (CVJ, 2008). Hay que tener en cuenta que esta problemática está asociada a la actual conflictividad social y política, como las ocupaciones de tierras, la violencia en desalojos o la destitución del presidente Lugo.

La población entrevistada mostró una alta necesidad de conversar socialmente sobre lo ocurrido aunque como en otros contextos, las víctimas combinan una ambivalencia entre la necesidad de hablar con la existencia de aspectos que prefieren no compartir, seguramente asociadas a las emociones de culpa y vergüenza que se hacen especialmente emergentes en este colectivo.
Aun cuando en algunos estudios se ha mostrado que la participación en rituales transicionales como Comisiones de Verdad hace descender estas emociones negativas en la medida que se devuelve la culpa y la vergüenza a quienes ejercieron la violencia (Kayangara, 2008), en el caso paraguayo, si bien la mayoría de las víctimas prestaron su testimonio y además sintieron que éste fue tenido en cuenta a la hora de la realización del informe final, no se superaron estas emociones: al contrario, haber dado el testimonio se asocia con más culpa y más tristeza (en la línea de lo planteado por Brounéus, 2008; Kaminer et al, 2001; Hamber, 2007; Rimé et al, 2011), aunque también se hace saliente una menor desafección política luego de la dictadura. Este resultado es coherente con el estudio guatemalteco (Cabrera, 2006), donde las víctimas que participaron en los juicios, a pesar de su gran coste emocional, expresaron sentir una mayor sensación de eficacia colectiva y de empoderamiento político.

Precisamente, aunque la violencia represiva pretenda operar como una forma de control social extrema dirigida a desmovilizar a la población, este estudio muestra que lejos de conseguirlo, cuanto mayor ha sido el nivel de exposición a la violencia de la población, menos ha descendido su interés por cuestiones sociales o políticas; a la inversa, se sugiere que la represión ha aumentado su interés sociopolítico, de forma similar a lo ocurrido en otros contextos (Arnoso y Pérez-Sales, 2013).

Por otro lado, se ha encontrado un gran conocimiento de las medidas transicionales que se han implementado, en contraste con lo hallado en otros contextos donde el nivel de información ha resultado menor (Cárdenas et al., 2013; Arnoso, 2012), a excepción de del Museo Virtual, que bien puede deberse a la aun escasa difusión de la web o al parcial acceso a las tecnologías en las zonas rurales. 
Asimismo, se constató una alta percepción de eficacia, tanto de la CVJ como de las disculpas emitidas por el ex presidente Lugo. Llama la atención la percepción de que ésta ha sido útil para juzgar a los responsables, aun cuando en el país no se han celebrado juicios penales como los celebrados en otros países latinoamericanos. Esta percepción puede responder a que simplemente contar con un informe que de veracidad a los relatos de las víctimas, sea evaluado como una condena social a los responsables de la represión, aun cuando no haya un castigo penal para ellos.

La población mostró que el Juicio y Castigo es un requisito necesario si se quiere hablar de reconciliación, objetivo al cual la población se mostró muy partidaria, a la inversa de lo encontrado en otros contextos, donde las víctimas principalmente suelen tener un discurso beligerante frente a la reconciliación, asociándola con el olvido, sobre todo allí donde se ha consagrado la impunidad (Arnoso, 2012). Pese a la deseabilidad expresada, las víctimas directas fueron las que menos favorables de mostraron.

Esta deseabilidad de la reconciliación se asoció a mejor valoración del clima emocional, un menor nivel de participación social y una mayor desafección política luego de la dictadura.

En cualquier caso, el nivel de participación de la población en actividades de derechos humanos 0 de organizaciones de afectados es alto y con pocas diferencias en función del nivel de afectación, mostrando en este sentido un amplio acompañamiento comunitario a las víctimas y de defensa de los derechos que les asisten como comunidad. Este resultado contrasta con la experiencia en otros contextos donde la participación en este tipo de actividades ha correspondido casi exclusivamente a las víctimas (Arnoso, 2012) y seguramente se deba a la gran extensión de la violencia en la región. Será necesaria contrastar esta información con muestras de otras regiones del país donde las víctimas constituyen un grupo más aislado para comprender las dinámicas comunitarias de la violencia y su reparación. 
REFERENCIAS

Arnoso, M. (2012). Dictadura Militar en Jujuy (1976-1983): Representaciones del Pasado, la Justicia y la Reparación. San Salvador de Jujuy: Editorial de la Universidad de Jujuy.

Arnoso, M. y Pérez-Sales, P. (2013). Representaciones sociales de la víctima: entre la inocencia y la militancia política. Psicoperspectivas, 12 (1), 50-71.

Avruch, K. (2010). Truth and Reconciliation Commissions: Problems in Transitional Justice and the Reconstruction of Identity. Transcultural Psychiatry, 47(1), 33-49.

Bar-Tal, D. (2011). Intergroup Conflicts and their Resolution: Social Psychological Perspective. Hove and New York: Psychology Press: Frontiers of Social Psychology Series.

Beristain, C. (2005). Reconciliación y democratización en América Latina: un análisis regional. Papel de las políticas de Verdad, Justicia y Reparación. In: IIDH (Ed.), Verdad, justicia y reparación. Desafíos para la democracia y la convivencia social. San José: International IDEA.

Beristain, C., Páez, D., Rimé, B. \& Kanyangara, P. (2010). Psychosocial effects of participation in rituals of transitional justice: A collective-level analysis and review of the literature of the effects of TRCs and trials on human rights violations in Latin America. Revista de Psicología Social, 25(1), 47-60.

Bobowik, M., Bilbao, M. A. \& Momoitio, J, (2010). Psychosocial effects of forgiveness petition and "self-criticism" by the Basque Government and Parliament directed to the victims of collective violence. Revista de Psicología Social, 25(1), 89-100.

Brouneus, K. (2008). Truth-Telling as Talking Cure? Insecurity and Retraumatization in the Rwandan Gaçaca Courts. Security Dialogue, 39(1), 55-76.

Cárdenas, M., Páez, D. y Rimé, B. (2013). El impacto psicosocial de los procesos transicionales en Chile: evaluación de los efectos de las Comisiones Nacional de Verdad y Reconciliación y Prisión Política y Tortura". Revista de Psicología Social 28(2), 145-156.

Comisión Verdad y Justicia (2008). Tierras Mal Habidas. Informe Final, Anive haguâ oiko.
Asunción: Comisión Verdad y Justicia Paraguay - CVJ.

Gibson, J. (2004). Overcoming Apartheid: Can Truth Reconcile a divided Nation? New York: Russell Sage Foundation.

Hamber, B. (2007). Reparations as Symbol: Narratives of Resistence, Reticence, and Possibility in South Africa. In: J. Miller y R. Kumar (Eds.), Reparations: Interdisciplinary Inquiries. New York: Oxford University Press.

Jelin, E. (2002). Las conmemoraciones: Las disputas en las fechas "infelices". Madrid: Siglo XXI.

Jelin, E. y Langland, V. (2003). Monumentos, memoriales y marcas territoriales. Madrid: Siglo XXI

Kaminer, D., Stein, D., Mbanga, I., \& ZunguDirwayi, N. (2001). The Truth and Reconciliation Commission in South Africa: relation to psychiatric status and forgiveness among survivors of human rights violations. British Journal of Psychiatry, 178, 373-377.

Kanyangara, P. (2008). Justice et Verite après un Genocide: Impact Psychosocial sur le Pardon et la Reconciliation (Tesis doctoral). Faculte de Psychologie, Louvain, Belgique.

Kanyangara, P., Rimé, B., Philippot, P. \& Yzerbit, V. (2007). Collective Rituals, Emotional Climate and intergroup perception: Participation in Gacaca Tribunals and the Assimilation of the Rwandan Genocide. Journal of Social Issues, 63, 273-288.

Lira, E. (1991). Psicología de la amenaza política y el miedo. Santiago de Chile: Chileamerica. CESOC.

Lykes, B., Beristain, C. y Cabrera, M. L. (2007). Political Violence, Impunity, and Emotional Climate in Maya Communities. Journal of Social Issues, 63, 369-386.

Nadler, A., Malloy, Th., y Fisher, J. (2008). The social psychology of intergroup reconciliation. Oxford: Oxford University Press.

Navarro-García, S., Pérez-Sales, P., Martínez, J., Barczay, D., Mendez-Castillo, A., Woltke, C., Lemus, L., López-Sandoval, M., Fernández-Pinto, I. y Eiroá-Orosa, F. (2009). Exhumaciones, verdad y justicia en Guatemala, estudio de opinión a nivel nacional. Guatemala: Equipo de Estudios Comunitarios y Acción Psicosocial. 
Páez, D., Basabe, N. y González, J. L. (1997). Social Processes and Collective memory. In: J. Pennebaker, D. Páez y B. Rimé (eds), Collective memory of Political Events, Hillsdale, NJ: Lawrence Erlbaum

Pérez-Sales, P. y Navarro-García, S. (2007). Resistencias contra el olvido. Trabajo psicosocial en procesos de exhumaciones. Barcelona: Gedisa

Pérez-Sales, P., Vázquez, C. y Arnoso, M. (2009). Aprendizaje postraumático individual y colectivo ante situaciones de terrorismo y violencia colectiva: Datos para un debate. En: I. Márquez, A. FernándezLiria \& P. Pérez-Sales (Eds.), Violencia y salud mental. Madrid: Asociación Española de Neuropsiquiatría, pp. 349-376.

Rimé, B., Kanyangara, P., Yzerbyt, V. \& Páez, D. (2011). The impact of Gaçaca tribunals in Rwanda: Psychosocial effects of participation in a truth and reconciliation process after a genocide. European Journal of Social Psychology, 41(6), 695706. doi: 10.1002/ejsp.822

Sikkink, K. y Booth-Walling, C. (2007). The Impact of Human rights in Latin America. Journal of Peace Research, 44(4), 427445.

Tavuchis, N. (1991). Mea Culpa: a Sociology of Apology and Reconciliation. Stanford: Stanford University Press.

Valencia, J., Momoitio, J. y Idoyaga, N. (2010). Social Representations and Memory: The Psychosocial impact of the Spanish "Law of Memory", related to the Spanish Civil War. Revista de Psicología Social, 25(1), 73-86. 